\title{
Outlining multi-purpose forest inventories to assess the ecosystem approach in forestry
}

\author{
P. CORONA ${ }^{1} \&$ M. MARCHETTI ${ }^{2}$ \\ ${ }^{1}$ Dipartimento di Scienze dell'Ambiente Forestale e delle sue Risorse, Università della Tuscia, Viterbo, Italy, and ${ }^{2}$ Dipartimento \\ di Scienze e Tecnologie per l'Ambiente e il Territorio, Università del Molise, Isernia, Italy
}

\begin{abstract}
A summary and discussion of selected published results on the current and potential role of forest inventories (with particular reference to the national ones) are presented in the light of the challenges posed by society and policy decisions in the environmental sector. The analysis concentrates mainly on the ecological and socio-economic aspects of the question and on forest inventories' potential contribution to achieving sustainable forest management.
\end{abstract}

Key words: National forest inventories, biodiversity monitoring, systemic silviculture, forest geomatics

\section{Introduction}

The world's precious natural resources and their sustainable management have received significant attention over recent decades. This is certainly the case in the common vision of forestry and of the forest sector, which currently revolves around the idea of what it can contribute to modern society, by delivering social, economic, environmental and cultural benefits on a sustainable basis. Documents and decisions at national and international levels also reflect this attitude, such as the Forest Action Plan of the European Union (EU) which foresees:

\footnotetext{
"in the future forests should positively affect the quality of people's lives, providing a pleasant living environment, opportunities for recreation and preventive healthcare, while at the same time maintaining and enhancing environmental amenities and ecological values. Forests are to maintain the spiritual and cultural heritage they contain. Multifunctional forestry ought to continue supplying raw materials for renewable and environmentally friendly products and playing an important role in the economic development and prosperity of Europe, in particular of rural areas".
}

Over approximately the last 30 years knowledge acquisition processes in forestry have focused on new approaches for multipurpose information (Lund, 1998; Corona et al., 2002). Traditionally, data on forests and forestry have been collected through user-driven sampling procedures, usually in the context of forest inventories (Table I). Albeit national forest inventories have followed different historic development paths in different countries and are still evolving (this also applies to continental and global schemes: e.g. the EU's Forest Monitoring Centre and the United Nations Food and Agriculture Organization's [FAO] Forest Resource Assessment), it is widely proven that, with feasible investments, they provide useful results for national socio-economic development. Hence the forest research community has been active in devising methods and tools to advance the discipline frontier.

For many years forest inventories were concerned with assessing the sustainability of the productive function of forests, i.e. their growing stock and growth rate and the extent to which they were utilized. However, over recent decades policy formulation and strategic planning have been the main goals. There is an increasing demand for information on non-productive functions of forests due to the requests of policy makers and the public's perception of forests as one of the last close-to-nature landscape elements. This type of enhanced data is not only a

Correspondence: Piermaria Corona, Dipartimento di Scienze dell'Ambiente Forestale e delle sue Risorse, Università della Tuscia, Via S. Camillo de Lellis s.n.c., I-01100 Viterbo, Italy. Tel.: +39 0761357425. Fax: +39 0761357389. E-mail: piermaria.corona@unitus.it 